\title{
BORTEZOMIB INDUCED SUBCONJUNCTIVAL HEMORRHAGE
}

\author{
NAVIN PATIL ${ }^{1}$, BALAJI 0 ${ }^{1}$, KARTHIK S UDUPA ${ }^{2 *}$, KARTHIK RAO ${ }^{3}$
}

${ }^{1}$ Department of Pharmacology, Kasturba Medical College, Manipal, Karnataka, India. ${ }^{2}$ Department of Medical Oncology, Kasturba Medical College, Manipal, Karnataka, India. ${ }^{3}$ Department of Internal Medicine, Kasturba Medical College, Manipal, Karnataka, India. Email: udupa.karthi@manipal.edu

Received: 03 January 2017, Revised and Accepted: 14 January 2017

ABSTRACT

Many drugs are used in the treatment of multiple myeloma but thalidomide, lenalidomide, bortezomib, and dexamethasone and their combination remain the main stay of treatment. The molecular formula of bortezomib is $\mathrm{C}_{19} \mathrm{H}_{25} \mathrm{BN}_{4} \mathrm{O}_{4}$ and its chemical name is (3-methyl-1-(3-phenyl-2-pyrazin-2ylcarbonylamino-propanoyl) amino-butyl) boronic acid. Mechanisms by which it acts is usually by 26 SProteasome inhibition leading to degradation of anti-apoptotic proteins. Bortezomib is known to cause many side effects. Hence, we report a rare case of bortezomib-induced subconjunctival hemorrhage in our tertiary care hospital.

Keywords: Bortezomib, Adverse effect, Proteaosome inhibition, Subconjunctival hemorrhage.

(c) 2017 The Authors. Published by Innovare Academic Sciences Pvt Ltd. This is an open access article under the CC BY license (http://creativecommons. org/licenses/by/4. 0/) DOI: http://dx.doi.org/10.22159/ajpcr.2017.v10i4.16907

\section{INTRODUCTION}

Multiple myeloma is a hematological malignancy of plasma cell origin. Many drugs are used in the treatment of multiple myeloma but thalidomide, lenalidomide, bortezomib, and dexamethasone and their combination remain the main stay of treatment. Time to disease progression was found superior with bortezomib when compared to other drugs. It is known to cause many adverse effects which include nausea, vomiting, constipation, insomnia, blurred vision, skin reactions, muscle, and joint pain [1]. Some of the ocular side effects include bilateral eye soreness, itching, redness, blepharitis, meibomitis, and multiple chalazion [2]. Hence, we report a rare case of bortezomib-induced subconjunctival hemorrhage in our tertiary care hospital.

\section{CASE REPORT}

Informed consent was obtained from the patient. A 55-year-old female, a known case of multiple myeloma post radiation therapy was started on chemotherapy with bortezomib, thalidomide, and dexamethasone combination on July 2015 and had completed six courses as on February 2016. The patient was planned for bone marrow transplantation on mid February 2016. On the month of February patient walked in with complaints of severe redness and itching of right eye. Conjunctivitis was ruled out and ophthalmic examination showed patient vision to be normal and patient was diagnosed of subconjunctival hemorrhage (Fig. 1). Causes of subconjunctival hemorrhage were ruled out which includes local trauma, ocular inflammations, orbital injuries, conjunctival tumors, ocular amyloidosis, ocular adnexal tumors, and contact lens use. This led to the diagnosis of drug-induced subconjunctival hemorrhage. Bortezomib was suspected to be the causative agent and it was supported with the evidence of reduced platelet counts in biochemical assessment. Platelet counts became very low after six cycles of bortezomib and values are tabulated as follows (Table 1). All other lab parameters were normal, and patient was treated with hot water compress to treat subconjunctival hemorrhage. Subconjunctival hemorrhage resolved slowly and platelet counts also improved during the next follow-up visit.

\section{DISCUSSION}

Multiple myeloma is regarded as one of the most common hematological malignancy and is of plasma cell origin with an annual incidence of $4.3 \%$ per 100000 in the United States with age-adjusted to 2000 population. It is more common in males and in blacks when compared to females and whites, respectively. Treatment of multiple myeloma has evolved over time starting from alkylator-based therapies to stem cell transplantation, bone marrow transplantation to use of novel anticancer drugs targeting tumorigenesis pathways with latest being monoclonal antibodies. First line drugs in both the induction as well maintenance regimens currently include thalidomide, lenalidomide, bortezomib, and dexamethasone used in different combinations [3]. The ubiquitinproteasome pathway plays a major role in various cellular events in the process of tumorigenesis in multiple myeloma.

Bortezomib (VALCADE at formerly PS 341) is a proteasome inhibitor approved by Food and Drug Administration in May 2003 [4] for treatment of newly diagnosed cases of multiple myeloma as well as relapse/refractory multiple myeloma. The molecular formula of bortezomib is $\mathrm{C}_{19} \mathrm{H}_{25} \mathrm{BN}_{4} \mathrm{O}_{4}$ and its chemical name is (3-methyl-1(3-phenyl-2-pyrazin-2-ylcarbonylamino-propanoyl) amino-butyl) boronic acid. Mechanisms by which it acts is usually by $26 \mathrm{~S}$ Proteasome inhibition leading to degradation of anti-apoptotic proteins. This further protects proapoptotic proteins from degradation resulting in programed cell death in malignant cells. It has been found that multiple myeloma cells show increased expression of nuclear factor-kappa B (NF- $\kappa \mathrm{B}$ ). Bortezomib inactivates NF- $\kappa \mathrm{B}$ pathway. In multiple myeloma, there is a degradation of IКB due to phosphorylation by IKK which leads to translocation of NF- $\mathrm{KB}$ into the nucleus causing transcription of a series of pro-survival genes. Proteasome inhibition prevents the activation of NF- $\mathrm{KB}$ and hence forth increases the death of malignant cells. Major side effects include generalized weakness, gastrointestinal symptoms, low platelet counts, insomnia, bone and joint pain, and peripheral neuropathy [1]. Usually, anticancer drugs are known to cause many side effects but ocular side effects are very rare and in a study conducted recently with 130 patients in a tertiary care hospital only $10 \%$ had eye disorders when compared to another system examination [5]. Ocular side effects include blepharitis, conjunctivitis, chalazion, and severe uveitis [2]. In our case, patient after receiving six cycles of bortezomib-based chemotherapy developed severe thrombocytopenia which led to subconjunctival hemorrhage. All other causes were ruled out and causality assessment as per Naranjo's scale was done, and a probable causal relationship was established [6]. 


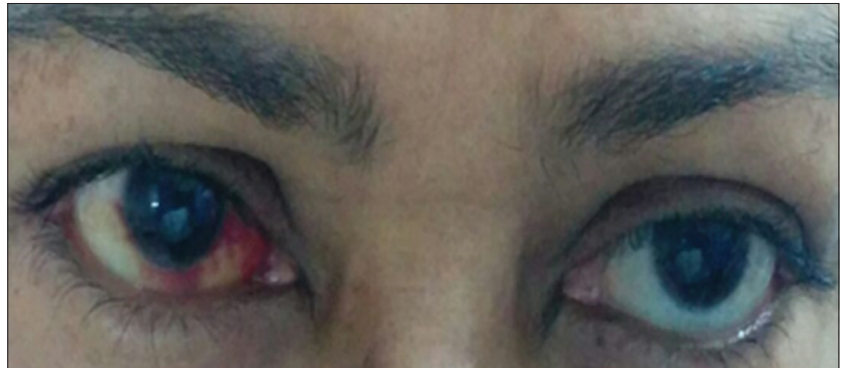

Fig. 1: Subconjunctival hemorrhage

Table 1: Platelet count before and after six cycles of bortezomib

\begin{tabular}{ll}
\hline Bortezomib cycle & Platelet counts \\
Before first cycle & $257 \times 10^{3} / \mathrm{UL}$ \\
After sixth cycle & $73 \times 10^{3} / \mathrm{UL}$ \\
At last follow-up visit & $208 \times 10^{3} / \mathrm{UL}$ \\
\hline
\end{tabular}

Table 2: Adverse drug reaction assessment

\begin{tabular}{ll}
\hline Naranjo's scale & Probable \\
Hartwig's scale & Mild severity \\
Thornton's scale & Not preventable \\
\hline
\end{tabular}

Adverse reaction was found to be mildly severe and not preventable as per Hartwig's severity scale [7] and Thornton's preventability scale [8], respectively (Table 2).

\section{CONCLUSION}

Multiple myeloma, one among the most common hematological malignancy and bortezomib being the first line drug of choice proper adverse drug monitoring is essential. Since a probable causal relationship is established in this case, further prospective studies can be undertaken to evaluate the incidence of ocular side effects associated with bortezomib.

\section{REFERENCES}

1. Chen D, Frezza M, Schmitt S, Kanwar J, Dou QP. Bortezomib as the first proteasome inhibitor anticancer drug: Current status and future perspectives. Curr Cancer Drug Targets 2011;11(3):239-53.

2. Puri S, Joshi J, Derman O, Kornblum N, Verma A, Braunschweig I, et al. Ocular complications of bortezomib therapy in multiple myeloma. Blood 2014;124(21):5743.

3. Kyle RA, Rajkumar SV. Multiple myeloma. Blood 2008;111(6):2962-72.

4. Rambabu C, Venkatrao S, Ramu G, Ganesh M. Estimation of bortezomib in bulk and its pharmaceutical dosage forms by using a novel validated accurate reverse phase high performance liquid chromatography. Int J Pharm Pharm Sci 2011;3(3):303-5.

5. Kirthi C, Azra A, Reddy M, Ali SA, Yerramilli A. A study on the adverse effects of anticancer drugs in an oncology center of a tertiary care hospital. Int J Pharm Pharm Sci 2014;6(2):580-3.

6. Naranjo CA, Busto U, Sellers EM, Sandor P, Ruiz I, Roberts EA, et al. A method for estimating the probability of adverse drug reactions. Clin Pharmacol Ther 1981;30(2):239-45.

7. Hartwig SC, Siegel J, Schneider PJ. Preventability and severity assessment in reporting adverse drug reactions. Am J Hosp Pharm 1992;49(9):2229-32.

8. Schumock GT, Thornton JP. Focusing on the preventability of adverse drug reactions. Hosp Pharm 1992;27(6):538. 